\title{
Catalytic Nanocrystals Electrochemically Formed in Active Mesoporous Nanocomposites
}

\author{
G. S. Park*, H. S. Kim*, S. G. Doo*
}

* Analytical Engineering Center \& Materials Laboratory, Samsung Advanced Institute of Technology, P. O. Box 111, Suwon 440-600, Korea

Mesoporous nanocomposites with active metal crystals and amorphous phase frameworks reveal electrochemically superior properties by increasing the structural stability, electronic conductivity, and surface area. Recently, the use of surfactant mediated $\mathrm{SnO}_{2}$ and tin phosphates has been reported in Li rechargeable batteries [1-2]. Here, we describe the growth of catalytic nanocrystals in mesoporous nanocomposites that leads to non-collapsible mesopore structure with a very large BET surface area (205 $\mathrm{m}^{2} / \mathrm{g}$ ). In order to clarify how the catalytic nanocrystals are formed in the nanocomposites during the chargedischarge reaction, we carefully investigated using HR-TEM, annular dark-field (ADF) STEM, nano-area electron diffraction (NED), and EELS techniques.

Mesoporous tin phosphate was prepared by mixing $9.0 \mathrm{~g} \mathrm{SnF}_{2}$ and $12 \mathrm{~g} \mathrm{H}_{3} \mathrm{PO}_{4}$, followed by dissolution in distilled-deionized water (DDW). Twelve grams of SDS (sodium dodecyl sulfate) was dissolved in $40 \mathrm{ml}$ of DDW, and this solution was added to a solution of $\mathrm{SnF}_{2}$ and $\mathrm{H}_{3} \mathrm{PO}_{4}$. The mixture was stirred at $40^{\circ} \mathrm{C}$ for $1 \mathrm{~h}$ and loaded in an autoclave at $90^{\circ} \mathrm{C}$ for 5 days. The synthesized powders were annealed at $500^{\circ} \mathrm{C}$ for $5 \mathrm{~h}$, yielding mesoporous tin phosphates. After assembling the cell, it was charged to $1.5 \mathrm{~V}$ after discharging to 0 $\mathrm{V}$.

Figure 1A shows the ADF-STEM image of the annealed tin phosphates, which depicts a uniform distribution of mesopores in the whole area of sample with a contrast of dark dots. The cross-sectional HR-TEM image of the charged tin phosphates shown in Fig.1B clearly demonstrates that many nanocrystals, indicated by the arrows, have electrochemically grown at the wall frame surrounding the pores without collapsing the distribution of mesopores. The size of the pores and nanocrystals in Fig.1B is approximately $3.2 \mathrm{~nm}$ and 2 $\mathrm{nm}$, respectively. The image supports that the growth of nanocrystals occurs during the Li de-alloying (after charging at $1.5 \mathrm{~V}$ ) and the crystalline wall structure is effectively conserved without collapsing during the discharge and charge cycle. Figure 2B shows the radial intensity profile of an NED [3] pattern (Fig.2A) obtained from the nanocrystalline area shown in Fig.1B. The reciprocal distances of peaks 1 and 2 measured from the profile are $2.67 \mathrm{~nm}^{-1}\left(3.75 \AA\right.$ ) and $5.13 \mathrm{~nm}^{-1}$ (1.95 $\AA$ ), which corresponded to the (111) and (311) reflections of $\alpha-\mathrm{Sn}$ (FCC), respectively. In addition, the comparison of the EELS spectra, which obtained from the Sn nanoparticles used as the reference sample, the amorphous wall area of the annealed tin 
phosphate, and the nanocrystalline area of the fully charged sample, makes it clear that the nanocrystalline area shown in Fig. 1B is composed of pure Sn nanocrystals and amorphous lithium phosphate frameworks.

References

[1] F. Chen, M. Liu, Chem. Commun. (1999) 1829.

[2] E. Kim et al., Angewandte Chemie Int. Ed. Engl. 43 (2004) 5987.

[3] J. M. Zuo et al., Microscopy Research and Technique 64 (2004) 347.

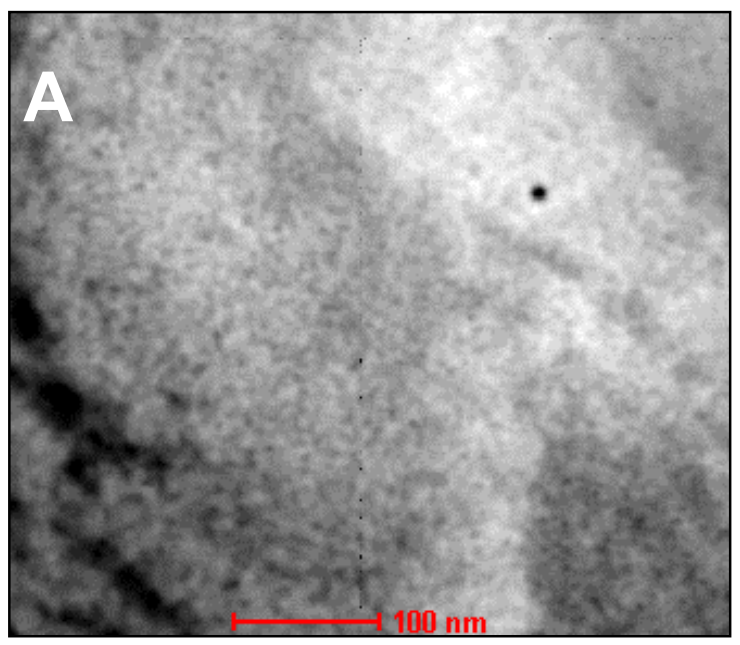

Fig.1. Cross-sectioned mesoporous tin phosphates after anealing at $500{ }^{\circ} \mathrm{C}$ for $6 \mathrm{~h}$ (A; STEM image), and charging at $1.5 \mathrm{~V}(\mathrm{~B}$; HR-TEM image).

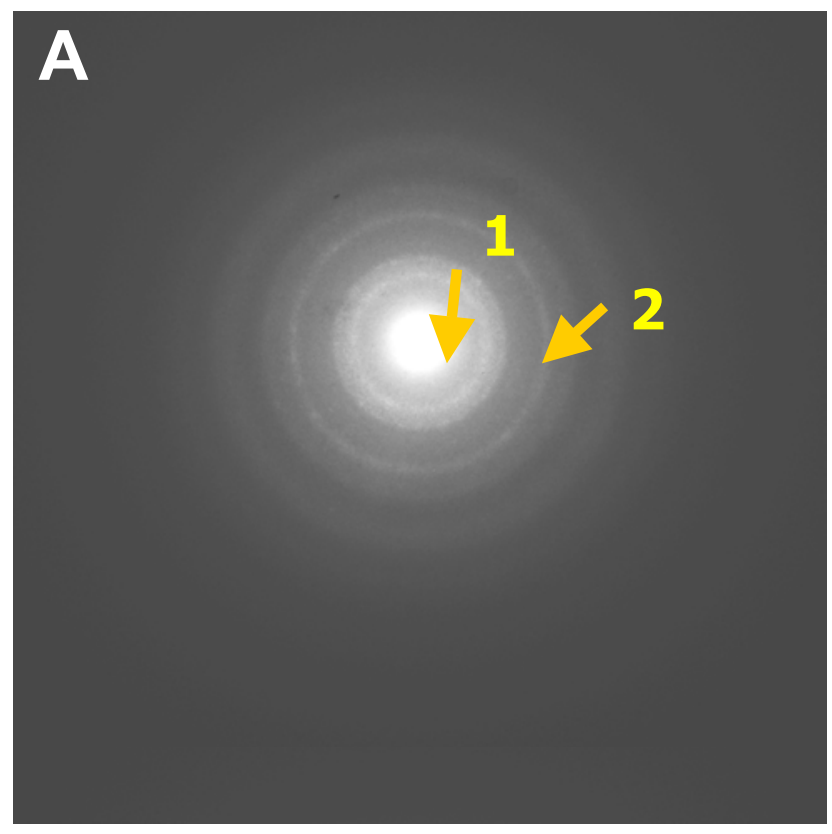

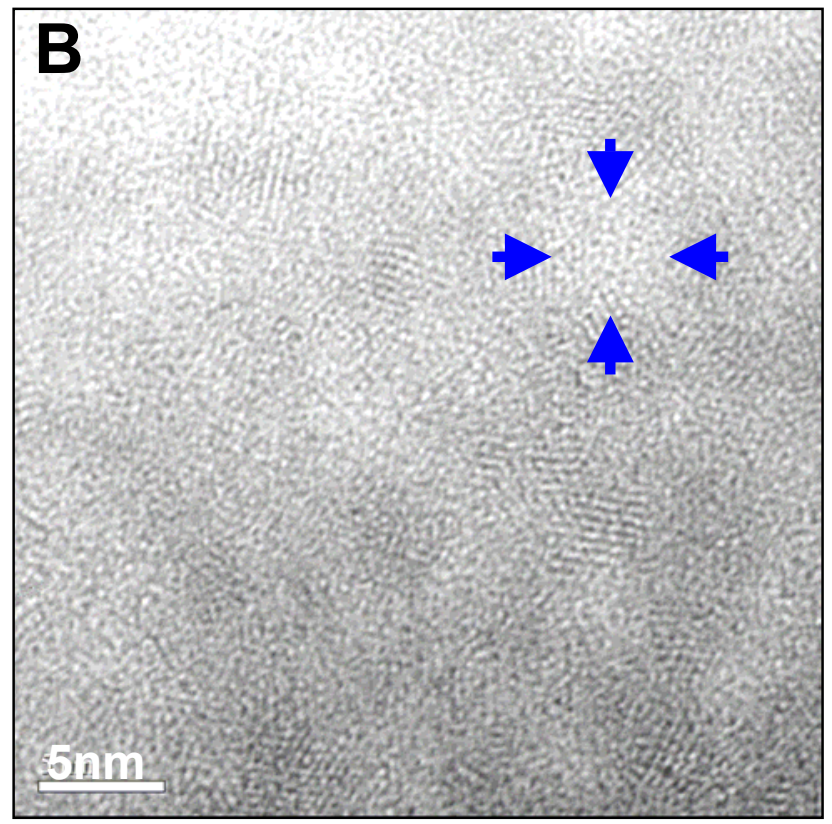

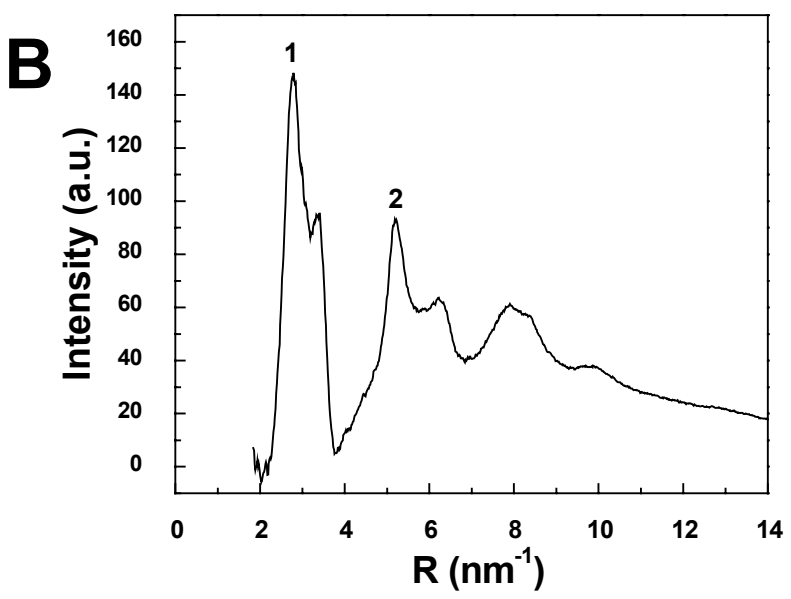

Fig.2. Nano-area electron diffraction (NED) pattern obtained from the nanocrystalline area shown in Fig. 1B (A) and its radial intensity distribution (B). 